\title{
Practice and Exploration of Online Education and Teaching during the Epidemic Situation——Taking Qingdao Teaching as an Example
}

\author{
Hong Zhang Lulu Ma \\ Qingdao University, Qingdao, Shandong, 266071, China
}

\section{ARTICLE INFO}

Article history

Received: 24 September 2020

Revised: 30 September 2020

Accepted: 9 October 2020

Published Online: 16 October 2020

Keywords:

Epidemic situation

Online teaching

Teaching practice

\begin{abstract}
The COVID-19 in now has disrupted the normal teaching schedule, but it did not stop the pace of education . Under the national call of "school suspension without suspension". Qingdao primary school as an example, started a new learning mode of "home-schooling", to minimum the impact of epidemic prevention and control on the teaching order. Qingdao City set the city's famous teachers, build diacritical marks teams, create quality courses. Each school undertakes the heavy responsibility, does not show the weakness, the teacher advances the battle, displays the teacher style, discusses the new mode of online education and teaching together.
\end{abstract}

\section{Introduction}

I n December 2019, COVID-19 suddenly struck, seriously threatened people's health and life safety, affected people's pace of life. With the fluctuation and impact of the COVIN-19 epidemic, the Ministry of Education has issued a notice to postpone the school term of the spring of 2020 after studying the resolution. Follow up with the notice on the work schedule. Normal school opening and teaching arrangements throughout the country have been seriously affected. Qingdao uses modern network technology to create a new teaching model to build a digital education system.

\section{Gathering of Students to Create Courses}

February 17,2020 classes an Qingdao begins as schedule, but different from the previous class mode. Qingdao Education Bureau was busy in it's education posts giving advice on how not to effect the teaching, during the epidemic period how not to affect students to give advice. "The regional supervisor part arranges the entire district famous teacher unifies to arrange the class instruction, the school exerts the lesson preparation group strength, concentrates prepares the lesson to teach" ${ }^{\left[{ }^{[1]}\right.}$ To form a "one-person class, the group with" situation, forming the characteristics of the times of the air classroom form. Qingdao Education Bureau to mobilize technical staff, network personnel to develop online education platform "infinite treasure". Take "infinite treasure" the online platform as the tool, take the city elite teacher as the intermediary, teaches the air classroom for the whole city student. Zhu Zhiting believes that "stopping classes and not stopping learning" can be called home distance education or home

*Corresponding Author:

Hong Zhang,

Qingdao University, Qingdao, Shandong, 266071, China;

E-mail:1785797890@qq.com. 
learning in essence. It is a distributed home learning that is forced to use diversified media tools during the period of epidemic prevention and control because it is unable to concentrate on classes face to face, ${ }^{\text {,[2] }}$. The Qingdao Education Bureau adheres to the standard of "comprehensive, quantity control and burden reduction" in the curriculum arrangement, strictly controlling the daily class time, three classes per day in the primary school stage, each class time is controlled within 20 minutes, and the overall class time is not more than 1 hour. Qingdao Education Bureau provides the best teachers and the best content for the students during the epidemic. It sets up a team of famous teachers to customize the course content together. The excellent course is a modern teaching mode that integrates famous school lecturers, excellent courseware, and advanced equipment. "The curriculum layout of the school has always been dominated by the teacher-oriented curriculum development, with the classical achievements of human civilization as the core content of the curriculum, the compilation of experts, the implementation of teachers, and the presentation of teaching materials with a rigorous system $^{,[3]}$. This is different from the previous teaching curriculum, and has the characteristics of the integration of disciplines the integration of knowledge types, extracurricular extension as one of the new teaching content.

\section{School Responsibilities, Network Teaching}

Two months have passed, and the Qingdao Education Bureau has set up a model for schools in all districts. Time to prepare was bought. Each school combines its own school characteristics and class form, from April 15 grade one to grade three began to teach of their own teaching. Zhong Qiquan believes that "the foothold in the combination of information technology and school education will change from the traditional technology standard of the curriculum standard, and information technology will be a basic element of all courses "[[4]. The teachers of each school use the nail software to simulate the exercise in advance, discuss the network problems and technical problems, record the micro video and forward it to the parents to help the parents solve the technical problems. According to their own characteristics, each school chooses live broadcast form and video conference mode, and then uses sharing to share courseware. "With the construction of information on the field of education in our country, the sharing of network education has become a new type of educational resources, which has improved the effect of classroom teaching and achieved remarkable teaching results" ${ }^{\text {"[j] }}$. By using the nail teaching platform, we can provide strong technical support for teachers, make the classroom have the way of "classroom teaching + online learning", and explore the effective mode of teacher-student interaction, classroom teaching and resource sharing.

\section{Online and Offline, Three-Dimensional Linkage}

Under the call of the Ministry of Education to "stop classes and not stop learning", under the leadership of the school, teachers through their own strengths, for students' needs and curriculum characteristics, junior teachers use video conferencing mode to power point sharing procedures and teach students. In order to achieve good interaction in students' class, teachers constantly explore, combine computer technology with curriculum, use al$\mathrm{t}+$ tab to switch pages, conduct teacher-student interaction and background student state management. On how to improve students' learning quality of online teaching, "Song Lingqing, Xu Lin and Li Yalong put forward the learning model of "teacher-parent-student" community framework model "[6]. In addition to his own research, Wu believes that "online teaching should be based on "learning ", and must adhere to the combination of teachers' online guidance and students' home learning in order to truly achieve their goals" ${ }^{\text {, }}$. However, it should not be ignored that "the role of parents plays an important role in family education, while the role of parents during the prevention and control of the new crown pneumonia epidemics is mainly authority, guide, partner and example ${ }^{,[8]}$ can effectively supervise students' learning quality. Our school class teacher, teacher, parents, students three points, three-dimensional linkage, together as the support frame of students.

\section{Conclusion}

After two and a half months, we have preliminarily proved the timeliness of "online teaching" and offline teaching, nail video conference and ait + tab page switching is equivalent to teachers' classroom, and online uploading homework and commenting on excellent homework are more intuitive and effective. Teachers' teaching and research talk and curriculum design more accurate in place, grinding exercises richer and diverse forms. It also "makes more teachers and students and parents aware of the importance of online education" ${ }^{,[9]}$. Although the epidemic situation affected all aspects of the teaching plan, but Qingdao City to cope with the trinity of teachers and schools to coordinate communication to ensure that students study methodically. This is the challenge of Qingdao education, but also a close combination between teachers and schools. 


\section{References}

[1] Haiyin He, Menghui Qiu. Exloration and Practice of "Air Classroom" under the Background of the Epidemic $[\mathrm{J}]$. China Education Informatization, 2020,15:77-79. (in Chinese)

[2] Zhiting Zhu. Confirm and do a good Job of "Suspending Classes without stopping School" during the Epidemic period[J]. China Electrochemical Education,2020,4:1-3. (in Chinese)

[3] Libo Zou. Comprehensive Practical Activities: Curriculum Development of School Characteristics based on Student Orientation[J]. Middle East Moral Education in Primary Schools,2016,12:41-44. (in Chinese)

[4] Qiquan Zhong . Developing the School Curriculum in the New Era: The Case of China's Curriculum Reform Policies and Strategies of Curriculum Reform in Our Country Think Dry [J]. Global Education Outlook (Foreign Educational Information),2001,1:14-20. (in Chinese)

[5] Ling Guo, Zerui Guo. A Study on the Development
Strategies and Methods of Network Education under the Influence of Data [J]. China Education Informatization Higher Education 2017,7:21-26. (in Chinese)

[6] Lingqing Song, Lin Xu, Yaxuan Li. Accurate Online Teaching + Home Learning Model: Learning during the Epidemic Way to Improving Students' Learning Quality[J]. China Audio-visual Education,2020,3:114-122. (in Chinese)

[7] Di Wu . Online Teaching be more Suitable to focus on "learning" [J]. China Audio-visual Education, 2020,4:6-7. (in Chinese)

[8] Zhonghua Wang,Ying Jia. On the Corner of Parents in Primary and Middle Schools during Epidemic Prevention and Control Color [J]. Teacher Training in Primary and Secondary Sschools,2020,4:1-3. (in Chinese)

[9] Chenxi Zhao. A Return to the Essence of Education by Keeping the Class Stop[J]. Ningbo Economy (Financial Viewpoint)2020,03:45-46. (in Chinese) 